
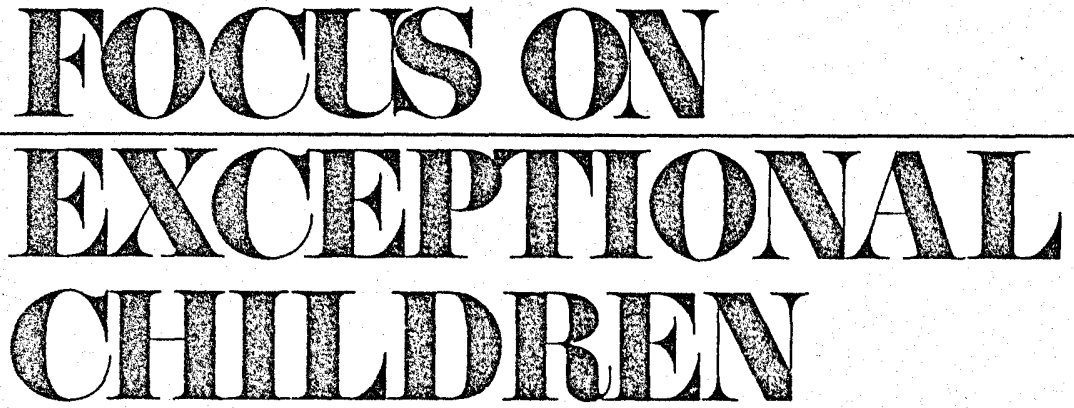

\title{
MAINSTREAMING FOR THE SECONDARY EDUCABLE MENTALLY RETARDED: IS IT DEFENSIBLE?
}

MAINSTREAMING
FOR THE SECONDARY EMR

\section{Gary M. Clark $^{1}$}

Mainstreaming-defined as an educational programming option for handicapped youth which provides support to the handicapped student and his teacher(s) while he pursues all or a majority of his education within a regular school program with nonhandicapped students-is a challenging and viable option of educational service delivery for some handicapped children and youth. It is challenging because of significant shifts in emphasis which must be made to provide support services rather than direct services to children. Although as of yet there are no reports of national prominence which provide empirical data supporting the movement, the logical and legal bases for such a thrust make it an important option for some handicapped students. However, if it is not necessarily appropriate for all handicapped students, some consideration must be given to the populations for which it may not be appropriate. Smith and Arkans (1974) have done this for the severely and profoundly retarded. This article will suggest yet another population-the secondary level educable mentally retarded.

When Dunn (1968) drew the issues of special class placement for the mildly retarded into focus for the field and gave impetus to a new era of professional self-analysis, he tried to document his position carefully concerning what types of changes should occur, the nature of the population about whom he was concerned, and the environments in which change should take place. One particular point made was a deliberate exclusion of secondary level educable mentally retarded from his population of concern (p. 6). This exclusion has been overlooked amid the sweeping changes in administrative structures and educational programming which has resulted from a rapid wake of court cases and strong advocacies of mainstreaming. There needs to be a re-examination at this time of some of the basic issues involved as they relate to adolescent educable mentally retarded in secondary school programs. The issues which follow are presented with some support for a particular point of view. They are also meant to be a means by which other viewpoints can surface and be considered.

1. Dr. Clark is a Professor of Special Education, University of Kansas, Lawrence. 
Issue 1

Given the logical and legal bases for the movement toward alternatives to special classes for elementary level mildly retarded children, are regular secondary programs as well suited for absorbing and serving educable mentally retarded students as elementary level programs?

One of Dunn's specific justifications for moving the mildly retarded back into the mainstream of elementary education was the capabilities of regular education to handle individual differences more readily than had been possible in the past. These capabilities were described in terms of trends and practices involving organizational changes, curricular changes, multimedia instructional resources, etc. One could add to this more facilitating environment the wider acceptance of the career education concept.

With the exception of some of the nation's more progressive secondary schools, the same claims for capabilities in dealing with individual differences at the secondary level, particularly high schools, cannot be made. Secondary schools are, in comparison to elementary schools, much more inflexible in administrative and programmatic change. For example, high school resistance to the career education concept is witnessed by the paucity of significant changes in programming since the movement began. Size, diversity, complexity, and the sacredness of the Carnegie unit are some of the obvious barriers to change, but there are other more subtle factors operating,

FOCUS ON EXCEPTIONAL CHILDREN is published monthly except June, July, and August as a service to those concerned with mentally retarded and emotionally disturbed children. This journal is abstracted and indexed in Exceptional Child Education Abstracts. Subscription rates, $\$ 9.50$ per year. Copyright 1975, Love Publishing Company. All rights reserved. Reproduction in whole or part without written permission is prohibited. Printed in the United States of America. Second class postage is paid at Denver, Colorado.

$$
\begin{gathered}
\text { Executive and Editorial Office } \\
6635 \text { East Villanova Place } \\
\text { Denver, Colorado } 80222 \\
\text { Telephone (303) 757-2579 }
\end{gathered}
$$

\section{EDITORIAL BOARD}

Edward L. Meyen

University of Kansas
Glenn A. Vergason Georgia State University

Richard J. Whelan University of Kansas Medical Center
Sallie Carmachel Keeney Managing Editor
Stanley F. Love Publisher including subject matter area "empires," greater activism in teacher negotiating units, academic competitiveness with other schools, and reduced responsibility for each student's total development.

\section{Issue 2}

Given the logical and legal bases for providing for the needs of all students, is the regular class the most advantageous current alternative in providing for the educable mentally retarded at the secondary level?

To discuss this issue and present a point of view, one must make certain assumptions that become basic to arguments supporting that point of view. The following assumptions have been accepted by the writer:

1. The higher one goes up the grade-level hierarchy, the greater the discrepancies among students in intellectual functioning, academic achievement, social experience, and personal maturity.

2. The higher one goes up the grade-level hierarchy, the greater the desire and/or demand by students for school to be related to immediate and near-future needs.

3. The higher one goes up the grade-level hierarchy, the greater the need by students to have greater identification and personal interaction with one or two significant adults who by proximity and commitment are readily available for guidance and counseling.

4. A democratic philosophy of education and a realistic philosophy of normalization do not dictate that all persons have the same educational experiences.

Based on an acceptance of these assumptions, the arguments which have been used against the special class in general can be challenged in relation to the secondary level class in particular.

Argument: Educable mentally retarded students make - as much or more progress in regular classrooms as they do in special classrooms.

Response: This argument is based on data from elementary, not secondary, level populations. On the contrary, there is some evidence to indicate that secondary special class programs are contributed to adult adjustment in the community for their participants (Porter \& Milazzo, 1958; Stephens \& Peck, 1968). 
Argument: Special class placement isolates the handicapped from normal peers.

Response: Secondary classes are not typically as self-contained as elementary special classes and are not as vulnerable on this point. Integration (not mainstreaming) in regular classes of music, art, physical education, homemaking, and industrial arts has been, and continues to be, a common practice in junior and senior high school special education classes. In addition, participation in extracurricular activities as well as both on-campus and offcampus work experiences have added to special students' exposure to and interaction with nonhandicapped peers. Only in the most restricted cases could this argument be justified against secondary special education classes. Certainly, it does not isolate students any more than some vocational education programs or other academic track options.

Argument: Special class placement stigmatizes the handicapped, resulting in loss of self-esteem and lowered acceptance by normal peers.

Response: Negative perceptions of a group or of individuals result primarily as a consequence of socially unacceptable or inappropriate behaviors, regardless of an educational grouping (Baldwin, 1958; Johnson, 1950). Inappropriate behaviors within a regular class will just as likely result in greater individual stigma, with accompanying loss of self-esteem and lowered acceptance by normal peers. It is interesting that the field has come full circle in this problem. The frustrations and pressures experienced by the educable mentally retarded in regular classes resulted in behaviors which were unacceptable and interpreted as indicative of poor mental health. The solution was seen to be their removal from that frustrating environment to one which would foster success, reduce frustration, relieve anxiety, and build positive self-concept. What was once seen as the source of the problem is now seen as the source of the solution.

The issue is not whether stigma exists, however, but rather whether the programming itself can demonstrate effectiveness in reducing or eliminating that stigma, raising self-esteem, and increasing the degree of acceptance by the nonhandicapped. We do not as yet have adequate data on this for adolescents.

Argument: The very existence of special classes encourages the misplacement of many handicapped persons, particularly children and youth from minority groups.

Response: As long as there are options for placement, there are opportunities for misplacement. With fewer options, misplacement is more likely to occur. If the options include only regular class placement or special class placement, minority group youth will be more likely to be misplaced in special classes. However, misplacement can be just as possible in regular classes as in special classes, if misplacement is interpreted similarly in both situations, i.e., inappropriate content and/or level of instruction.

If the special class is kept as one of several options, including learning centers, vocational education programs for handicapped or special-needs students, and mainstreaming with an effective career education component, misplacement is less likely to occur. Hopefully, recent court cases have made us sufficiently aware of the dangers of capricious placement and that placement based on lack of appropriate alternatives for minority group youths, or any youths for that matter, is an issue schools must face.

\section{Issue 3}

Given the logical and legal bases for meeting the needs of all children, are the decision makers who are extending the mainstreaming philosophy from elementary to secondary level giving appropriate attention to the consequences of curriculum focus as a result of their decisions? Meyen (1974) has stated the problem this way:

\footnotetext{
From a curriculum perspective, mainstreaming for handicapped children is presenting new curriculum problems for special educators. Unless we cope with these problems better and quicker than we did those encountered during the special class movement of the 1950s and 1960s, handicapped children will suffer and the field of special education may very well experience a major setback.... (p. 3)

Except for preventive measures-and in some cases, corrective measures-special education for most children involves curriculum. With most groups of exceptional children the focus is on providing an educational program which maximizes the child's performance and not on remediating his handicap. (p. 4)
}

The point of view being presented in this paper supports Meyen's statement and suggests that it is an even more crucial problem at the secondary level than at the elementary level. There can be no question that the curriculum focus of high school work-study programs for educable mentally retarded youth has been considered more relevant by that population than in previous years when the curriculum was a "watered-down" academic program. The holding power of the more relevant prevocational program has been demonstrated in report after 
report in not only reduced dropout statistics but in drawing former students back when they became aware of the new program.

The current curriculum focus in prevocational development and preparation for adult living is based on formal and informal follow-up studies of those who have been in special classes for the educable mentally retarded. This current focus is by no means adequate in terms of scope and sequence, but it is more on target than what is available in general education.

Vocational education, as a component of the regular school program, is appropriate in vocational content but deficient in adult living instruction and is generally inappropriate in terms of level of instruction. Vocational education and special education are on a collision course in the mainstreaming movement, and the resistance by vocational educators is still high. One of their defenses, and one which is undeniable at this point, is that mainstreaming explicitly involves support services for the handicapped, while few special educators are trained or qualified by experience to give technical assistance as one might in an academic subject.

If vocational education is not presently an available option, is the general education curriculum or track any more appropriate? Former U.S. Commissioner of Education S.P. Marland, Jr. has decried the ineffectiveness of general education and has referred to it as an "abomination" (Marland, 1971). The career education concept was conceived and developed with general education clearly in mind. However, until career education programs are operative and demonstrated to be effective, general education has little to offer but removal of group stigma and the appearance of normalization. If educators are more concerned about normalization and the avoidance of group stigma here and now than they are for normalization as adults and avoidance of individual stigma in the future, their concerns and priorities are questionable. Support for this interpretation of the principle of normalization is found in a publication by the National Association of Retarded Children (1972).

\footnotetext{
Although the normalization principle is useful in many situations, the fact that a technique is normative does not guarantee that it is the most effective. The developmental model suggests that program effectiveness should be gauged by the degree to which goals are reached rather than by the degree to which procedures are culturally normative. In some cases, normative procedures may fail to foster desirable behavior, whereas specialized procedures may accomplish desired goals. (p. 7)
}

A side issue to the problem of curriculum relevance for those secondary special education programs involved in a cooperative agreement with state vocational rehabilitation agencies is the basis for third party funding. This concerns the practice of obtaining additional federal funds for rehabilitation from state matching funds-in this case, teachers' and work-study coordinators' salaries. To use these salaries for matching purposes, the agencies must certify that the persons whose salaries are being used for matching are indeed performing a rehabilitation function. The criteria for certification are flexible but generally rest on the requirement that the content and instructional approach are prevocational in nature. Since early federal audits of this practice disallowed "watered-down" academics in special classes, there is no reason to believe that instruction focusing on support of students in an academic mainstream program would be allowable.

\section{Summary}

Mainstreaming as the only program option at the secondary level for educable mentally retarded adolescents is presently highly questionable for the following reasons:

1. We have no empirical evidence on adolescent retardates to indicate that movement from a partially developed -approach (but demonstrably more effective than previous programs) to a new, untried approach is appropriate.

2. The curriculum focus of mainstreaming at the secondary level is not congruous with what has been identified as the needs of adolescent retarded.

3. The basic assumptions posed for secondary special education programming do not indicate that regular secondary programs or tracks are appropriate.

4. Career education concept programs are not yet adequately established in junior and senior high schools.

5. Support personnel for vocational education teachers, the group most obviously needed for an appropriate mainstreaming approach, are not available.

6. The inflexibility of junior and senior high school policies and goals are not predictive of success for this population.

\section{Implications}

Some implications of this position can and should be drawn. 
1. Questioning of the appropriateness of mainstreaming at the secondary level for educable retarded adolescents in no way defends the inadequacies of the present special class model. There are tremendous gaps in existing special class programs in terms of curriculum development (scope and sequence), effective instructional approaches, adequate social training and opportunities, prevocational assessment, guidance and counseling, work adjustment training, and placement at appropriate levels of employment. Neither does it deny the probable benefits mainstreaming can provide for a larger number of educationally handicapped youths who have not been eligible for special class placement and have not been adequately served in the regular program.

2. Any school that has the capabilities of flexible school organization, adequate resource personnel, and a strong career education commitment should assume responsibility for empirically evaluating alternatives to special classes. Chaffin's (1974) sug. gested guidelines for administrators who are considering the initiation or expansion of a mainstreaming program should be followed. In addition, the evaluation should focus on the following questions ${ }^{2}$ :

a. What benefits will be gained from this alternative over present alternatives?

b. What curriculum restrictions will be placed on teachers?

c. What instructional support services are needed for each student and his/her teacher(s)?

d. What instructional materials are needed to support the student?

e. What curriculum resources are needed for complete programming?

f. What curriculum skills are needed by the special education staff?

g. What instructional skills are needed by the special education staff?

3. The reality of secondary schools rapidly moving into alternatives for special class placement for educable mentally retarded must not be overlooked by teacher

2. Adapted from a list of questions presented in Meyen (1974). education institutions, state departments, and school administrators. The responsibility for training, retraining, certification, and program development must be shared by all in a cooperative effort.

\section{Conclusion}

This point of view serves to raise questions, cautions, and issues which must be dealt with immediately. The bandwagon effect of mainstreaming should be avoided at all instructional levels, especially if conditions are not adequate. Moreover, the secondary level is particularly vulnerable to a "spirit of the times" program movement and may stand to lose gains which have been made in the last 15 years. It is hoped that the spirit of the times can be more broadly interpreted to suggested self-evaluation, appropriate goal setting, and innovative delivery rather than acceptance of one delivery model for educational services.

\section{REFERENCES}

Baldwin, W. D. The social position of the educable mentally retarded in the regular grades in the public schools. Exceptional Children, 1958, 25, 106-108.

Chaffin, J. D. Will the real "mainstreaming" program please stand up! (or ... should Dunn have done it?). Focus on Exceptional Children, 1974, 6, 1-18.

Dunn, L. M. Special education for the mildly retarded-Is much of it justifiable? Exceptional Children, 1968, 35, 5-22.

Johnson, G. O. A study of the social position of mentally handicapped children in the regular grades. American Journal of Mental Deficiency, 1950, 55, 60-89.

Marland, S. P., Jr. Career education now. Paper presented at the National Association of Secondary School Principals Convention, Houston, Texas, January 23, 1971.

Meyen, E. L. Mainstreaming: Some curriculum concerns. Paper presented at Kansas Federation of Council for Exceptional Children, Topeka, Kansas, March 1974.

National Association for Retarded Children. Residential programming for mentally retarded persons: A developmental model for residential services. Arlington, T'exas: National Association for Retarded Children, 1972.

Porter, R. B. \& Milazzo, T. C. A comparison of mentally retarded adults who attended a special class with those who attended regular school classes. Exceptional Children, 1958, 24, 410-412, 420.

Smith, J. O. \& Arkans, J. R. Now more than ever: A case for the special class. Exceptional Children, 1974, 40, 497-502.

Stephens, W. B. \& Peck, J. R. Success of young adult male retardates. Washington, DC: Council for Exceptional Children, 1968. 


\section{PREPARING COMPETENT TEACHERS: A NONCATEGORICAL COMPETENCY-BASED TEACHER TRAINING MODEL FOR SPECIAL EDUCATION}

\author{
Lee Courtnage, Richard Brady, Alice Suroski, \\ Rex Schmid ${ }^{3}$
}

During the past decade, the number of colleges and universities offering preparation programs for teachers of handicapped children have greatly expanded. From 1960 to 1967 , the number of such institutions increased from 16 to 243 and prepared over 32,000 persons (Heller, 1968). In 1969, 468 institutions offered programs in one or more areas of exceptionality enrolling 84,630 persons in fulltime, part-time, and extension study. Approximately 14,000 persons were graduated from these institutions in 1969 (Greer, 1970). According to a 1973 Federal government report (Elbers, 1973) nearly 400 colleges and institutions provide special education training and of these 304 received federal funding.

Amid this growth, however, an increasing number of investigators have questioned the efficacy of special education classes for the mildly handicapped (Cruickshank, 1971; Deno, 1970; Dunn, 1968; Johnson, 1962) and training programs for preparing teachers of the handicapped (Lilly, 1970, 1971; Nelson \& Schmidt, 1971; Blatt, 1966). The roots of such criticism are probably diverse: technological developments, changing societal conditions, a demand for accountability, dissatisfaction with traditional programs, new concepts of management, availability of federal monies for exploratory and experimental programs, litigation by parents and agencies against biased testing and labeling.

A growing number of critics have suggested that the placement of mildly handicapped children into special education classes and the subsequent labeling of them may, in fact, result in a negative rather than a positive change in their learning and social behaviors. Goffman (1963) suggested that the mere attachment of labels to children (mentally retarded, emotionally disturbed, etc.) may cause irreparable damage, primarily because the individual becomes the identity inferred by the label. Menninger (1964) stated "... the label applied to the illness becomes almost as damaging as the illness itself" (p. 12). Combs and

3. The authors are in the Division of Special Education, University of Northern lowa, Cedar Falls 50613.
Harper (1967) proposed that one of the major negative effects of labeling is the resultant teacher attitude toward the child: "... it is likely that the effect [of labeling] will be negative and result in the teacher behaving toward the child in a manner that will foster elements of his behavior that are making him exceptional" (p. 402).

The noncategorical teacher preparation strategy avoids labeling and is gaining popularity among special educators. Under such a system, training programs are specific to instructional methods rather than categories of children (Reynolds \& Balow, 1972). That is, teachers develop competency in diagnosis, remediation of behavior, and learning problems rather than becoming teachers of the mentally retarded or emotionally maladjusted.

Paralleling the development of the noncategorical teacher training strategy is the competency-based (or performance-based) training program. In describing traditional teacher education, Martin (1972) stated, "We are paying a great deal of attention to academic material, but little time is given to... the interpersonal relationship called teaching" (p. 319). That is, if a student experiences a specified number of courses in foundations and methods and undergoes some kind of student teaching experience he is competent to teach. By contrast, in competencybased programs performance goals are specified and agreed to in advance of instruction. The student must be able to demonstrate his ability to promote desirable learning or exhibit behaviors known to promote it. $\mathrm{He}$ is held accountable for attaining a given level of competency in performing the essential tasks of teaching while the training institution is held accountable for producing teachers with demonstrated instructional proficiency.

The essential elements of a competency-based teacher education program (Elam, 1971, pp. 6-7) are listed below:

1. Competencies (knowledge, skills, behaviors) to be demonstrated by the student are derived from explicit conceptions of teacher roles; stated so as to make possible assessment of a student's behavior in relation to specific competencies; and made public in advance.

2. Criteria to be employed in assessing competencies are based upon, and in harmony with, specified competencies; explicit in stating expected levels of mastery under specified conditions; and made public in advance.

3. Assessment of the student's competency uses his performance as the primary source of evidence; takes 
into account evidence of the student's knowledge relevant to planning for, analyzing, interpreting, or evaluating situations or behavior; and strives for objectivity.

4. The student's rate of progress through the program is determined by demonstrated competency rather than by time or course completion.

5. The instructional program is intended to facilitate the development and evaluation of the student's achievement of competencies specified.

While a variety of noncategorical, competency-based teacher education programs have been proposed (Reynolds \& Balow, 1972; Lilly, 1970, 1971), few have been implemented. Elfenbein (1972) mentions five institutions (Livingston University, College of Saint Scholastica, Southwest Minnesota State College, Teachers College-Columbia University, Weber State College) at which competencybased preparation programs are operational and eight institutions (Florida Agricultural and Mechanical University, University of Georgia, State University College at Buffalo, University of Texas at El Paso, Brigham Young University, University of Utah, Western Washington State College, University of Washington) in which a competencybased preparation program is a limited pilot program or a parallel program to more traditional training models. The purpose of this paper is to describe an operational, noncategorical, competency-based teacher educational program preparing teachers of the handicapped at the University of Northern Iowa (UNI).

\section{BACKGROUND AND RATIONALE}

The UNI program was developed through an evolutionary process. Prior to 1969 special education teacher training was a traditional program of academic course work with practical application limited to a student teaching experience. During that year a strong practicum component was added to the curriculum. With the arrival of new staff members in 1970, a systems approach was introduced for program planning. Under a 1971-72 BEH developmental grant, prescriptive teaching techniques (Peter, 1972a) were added as a part of the management component. With the support of a BEH training grant, implementation of the competency-based, noncategorical teacher education program began in 1972 when the entire curriculum was revised and reorganized. The revised curriculum reflected a sequenced, developmental preparation (disregarding labels) from a teacher-pupil interaction to a teacher-group interaction, to an interprofessional interaction. Conventional course content also was broadened in favor of the noncategorical approach at levels from preacademic through the secondary. Practicum experiences were matched with each major sequence of the new curriculum enabling a trainee to specialize in teaching at various levels.

The rationale of the UNI program has its foundations in three questions: When in time will the teacher function? Where will the teacher operate? What will be the teacher's role? These questions are basic to a functioning teacher training program within a specified setting and time. Performance criteria and terminal objectives can be formulated from the teacher-preparation program.

Rather than attempting to project future preparation needs of special teachers, the UNI staff elected to concentrate on developing a teacher who is prepared to adapt to many situations. That is, an attempt was made to develop a teacher with the requisite competencies to teach pupils representing a variety of problems in learning and behavior. The preparation of an individual able to succeed in many varied teaching positions was selected in lieu of cataloging specific teaching contexts. The role of the trainee completing the undergraduate program was seen as interactive with the use of strategies for making and implementing decisions tailored to the needs and characteristics of the pupils. The graduate program (M.A. and Ed.S.) focus was expanded to also include competencies requisite to the interprofessional role of therapeutic teacher, consultant, and administrator.

\section{CONCEPTUAL MODEL}

A conceptual model for professional training in special education was developed to guide the integration of didactics with practicum activities. The construction of this conceptual model was necessary to provide the structure for systematic planning of educational strategies. Because the conceptual model was a visual representation of the component elements of teaching, the UNI program staff were able to coordinate and integrate the existing curriculum components and clearly see which components needed to be reorganized or further developed. The model generated a language and context to facilitate communication between both faculty and students. Finally, the model served as the guideline for the development of evaluation procedures which measured the contribution of each curriculum component. 
The model and systematic training program allows the application of theories which facilitate the efficient ordering of environmental events expediting the learning process. However, if a particular theory of methodolgy is incorporated into teaching practice, it must be held accountable in terms of predictable and observable changes in the behavior of the children being taught by trainees. This places education within the same empirical context demanded of the physician, engineer, and the physicist. It is recognized, however, that teaching deals with human values which go beyond the physical cure, the construction of a mechanical device, or the discovery and application of a law of physics. The knowledge of human behavior which facilitates teaching efficiency needs to be tempered by humanistic values in the choice of both methods and goals.

The following statements review the principles upon which the model was based:

1. Teaching involves the conscious manipulation of environmental components to enhance both the rate and quality of learning as measured by the changes in the behavior of students.

2. The environmental components of teaching can be identified, observed, and quantified. Further, professionals can be systematically instructed in the use of the environmental components of teaching in order to maximize the learning efficiency of their students.

3. The evaluation of teaching effectiveness must ultimately rest in the measurement of the student's behavioral changes toward prestated and planned behavioral objectives.

4. Most learning is developmental in nature. Hence, teaching generally requires beginning where the student is and proceeding on an instructional continuum ranging from the simple and concrete to the complex and abstract. Further, the transfer of learned skills and knowledge is enhanced by ever closer approximations of the environment in which they are designed to operate.

The conceptual model was constructed upon the building blocks of (1) instructional methodology, (2) experience/practicum, and (3) educational management. The definitions and descriptions of these building blocks are given in the following statements:

1. Instructional Methodology includes imparting the skills of diagnosis, content determination and sequencing, curricular material utilization and task presentation procedures to the trainees to help them elicit behavioral changes in handicapped children as measured in Experience/Practicum and later professional practice.

2. Experience/Practicum is a sequential series of practica with handicapped children in which the trainee's effectiveness is measured by the direction, rate, and quality of the child's learning. This is observed through behavioral changes toward prestated, empirical objectives.

3. Educational Management includes the development of motivation, sensitivity to the affective domain, and the skills of behavior modification, educational organization, evaluation, communication, and discipline to enhance the learning of the trainee's pupils as measured in Experience/Practicum and later professional practice.

These building blocks are illustrated in Figure 1 while Figure 2 illustrates the organization of the building blocks into the training model. Throughout the entire training program, the ability of the trainee to integrate the academic learning from instructional methodology and educational management is tested with pupils in experience/practicum. Trainees are required to demonstrate their abilities at each step in the experience/practicum sequence before advancing. To enhance the transfer of learning from the instructional methodology and educational management to the experience/practicum blocks, each component course is systematically designed to interface with the experience/ practicum. The training program begins in Phase I, Individual Instruction. Phase I is centered around a one-to-one practicum in the Northern lowa Instructional Laboratory. Here, the trainee is able to apply both the instructional methodology and the educational management acquired in the more academic segments of the program. All three elements of Phase 1 must be taken concurrently by the trainee. This program is systematically supervised through the application of individual instruction (Peter, 1972b).

When a trainee has demonstrated the mastery of the basic teacher-child interaction in Phase $I$, he advances to Phase II. A formal screening of all trainees occurs at the completion of Phase I. Students who have not satisfactorily met the pre-stated performance criteria either recycle through Phase I or transfer to another area of professional preparation. Phase II is a more complex practicum experience in a group or classroom setting. This practicum is sequenced to allow the trainee to first apply 
Figure 1

BUILDING BLOCKS OF A TEACHER TRAINING MODEL

INSTRUCTIONAL METHODOLOGY

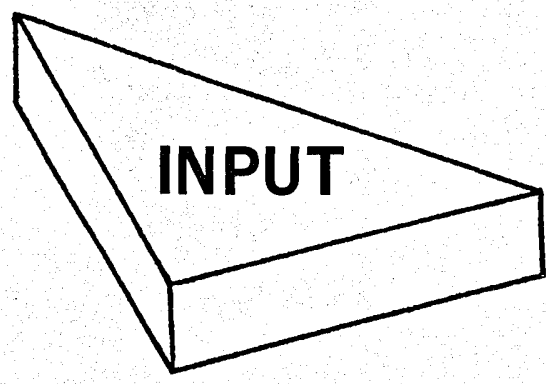

Imparting the skills of diagnosis, content determination and sequencing, material utilization, and task presentation procedures to the trainees to help them elicit behavioral changes in students.
EXPERIENCE

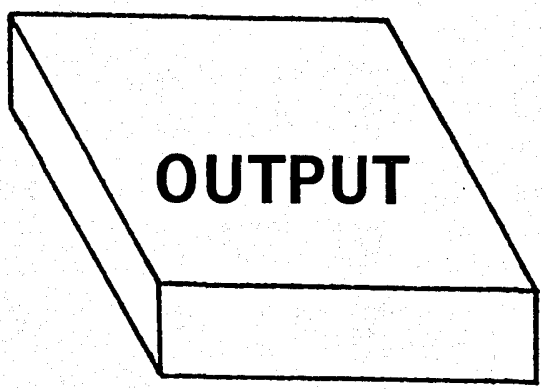

The application of instructional methodology and educational management skills to the instruction of students in practicum.
EDUCATIONAL MANAGEMENT

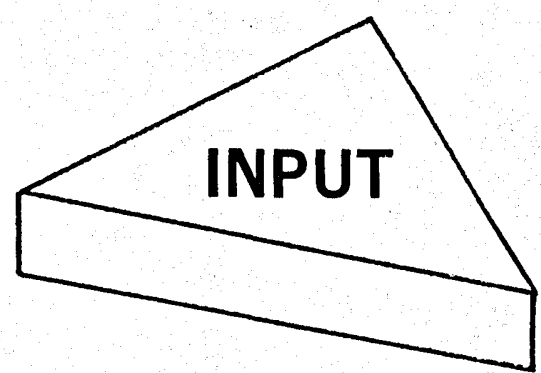

The development of motivation, sensitivity to the affective domain, and the skills of behavior modification, educational organization, evaluation, and communication to enhance efficiency in changing student behavior. one-to-one skills mastered in Phase I and then proceed step by step until he has demonstrated the ability to teach and orchestrate a group under the direction of a supervising teacher. In like manner, the sophistication of the instructional methodology and educational management is increased to support the experience/practicum in Phase II. As in Phase $I$, the trainee must enroll in the three components of Phase II concurrently.

In Phase III, at the M.A. level, the trainee is required to begin and complete a more advanced practicum. Experience/practicum in Phase III requires the trainee to initiate a therapeutic educational program, interact with other professionals, and work with community and lay support groups. The interprofessional trainee receives continued support through the input of increasingly sophisticated instructional methodology and educational management.

\section{ADVANTAGES OF THE TRAINING MODEL}

The model allows the trainee to develop the individualistic teaching procedures which are best suited to the needs of the child. Various approaches to teaching may be used as long as they produce observable gains toward the prescribed instructional goals. Indeed, the quick feedback of negative and positive results to the trainee tend to shape the individual in the use of procedures most effective for himself.

The versatility of the model is demonstrated by its adaptation to the noncategorical training approach. The need for training institutions to prepare teachers for work with the handicapped functioning at various cognitive and social levels has been recognized, but limited staff and relatively large student registrations often hamper the development of quality programs for each of the traditional, categorical areas of special education. In addition, existing patterns of funding and credentialing in many states require traditional designations for program graduates.

Analyzing educational needs of the handicapped in Iowa revealed a necessity for specialization of teachers at four levels of cognitive, personal, and social functioning: pre-academic, primary, intermediate, and secondary.

1. The pre-academic level is designed to develop the necessary teaching competencies to evaluate and 
Figure 2

CONCEPTUAL MODEL FOR PROFESSIONAL TRAINING

$\begin{array}{lll}\text { METHODOLOGY } & \text { EXPERIENCE } & \text { EDUCATIONAL } \\ \text { INSTRUCTIONAL } & & \text { MANAGEMENT }\end{array}$

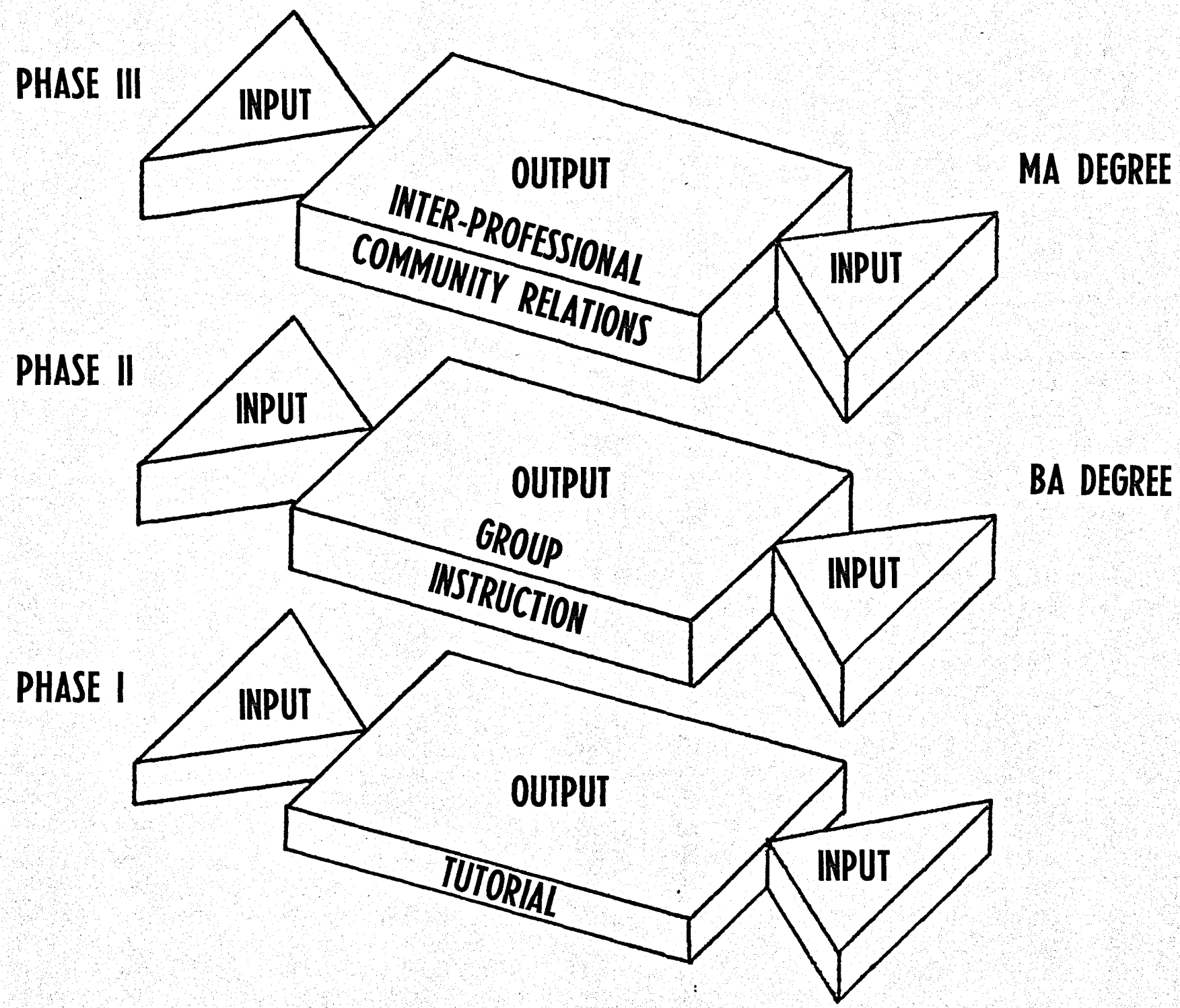

This conceptual model does not represent the complete educational program for those who receive degrees with special education majors at the University of Northern lowa. It represents a core which requires the integration of the total university experience to develop the complete professional. 
prepare the handicapped to function at the cognitive, personal, and social level of the child between the ages of 0.5 years. This would include the development of mobility skills, toilet training, language development, and self-help skills.

2. The primary level is designed to develop the necessary teaching competencies to evaluate and prepare the handicapped to function at the cognitive, personal, and social level of the child between the ages of 5.8 years. This would include academic readiness and appropriate personal and social skills.

3. The intermediate level is designed to develop the necessary teaching competencies to evaluate and prepare the handicapped to function at the cognitive, personal, and social level of the child between the ages of 8-12 years. This would include development and remediation of elementary skills in reading, mathematics, and written communication.

4. The secondary level is designed to develop the necessary teaching competencies to evaluate and prepare the handicapped to function at the cognitive, personal, and social level of the adolescent. This would include the development of vocational skills as well as continuous development and remediation of academic and social skills.

The trainee in the program usually selects two of the four functional levels (except elementary majors who may choose two of three levels). For example, a trainee majoring in elementary education for the handicapped might select the pre-academic and primary levels. The trainee would be assigned to the corresponding academic and practicum experiences and be required to demonstrate the requisite program performance criteria. The number of possible alternatives allow UNI trainees to individualize their training while providing flexibility for meeting shifting manpower needs without major program alterations. Table 1 illustrates the functional levels and their relationship to traditional categories and certification requirements.

\section{EVALUATION COMPONENTS}

The trainee's teaching competencies measured by Phase I and Phase II experience/practicum records and more customary supervision techniques are used to provide the empirical data necessary for operating the model. If a group of trainees are not able to demonstrate a required competency, the data permit the responsible model components to be identified, revised, and corrected. In this way, each academic course and practicum experience is judged against its ability to produce effective professionals for teaching handicapped children.

Two methods of follow up are being developed to determine the effectiveness of graduates from the training program. The first is an evaluation of the graduate's classroom effectiveness. This will indicate the transfer of program competencies into the field. The second is an evaluation of UNI graduates after their first and third years by administrators who have employed them. In addition to identifying inadequate program competencies, this will provide an evaluation of how well the graduate and his competencies are received by the employer.

Three groups provide external evaluation in the continuing development of the training program: the Special Education Professional Advisory Committee, the Special Education Student Advisory Committee, and the Special Education Consulting Team. In addition to the evaluation groups, an annual workshop for former students and a yearly inservice workshop for supervising teachers provides external feedback.

\section{SUMMARY AND FUTURE GOALS}

Based on a noncategorical, competency-based model, the Division of Special Education at the University of Northern Iowa provides a systematically integrated program designed to develop professional personnel with the requisite competencies to diagnose and teach, organize and supervise programs, evaluate instructional programs, and train professional educators to implement programs for children and youth manifesting retardation, behavioral, learning, and multiple handicaps. Traditional categories of special education have been de-emphasized and a systems approach applied to guide the integration of didactics with practicum activities. The training program model is constructed upon the building blocks of instructional methodology, experience/practicum, and educational management.

Specific objectives of program development over the next three years are (1) to add a research and delivery component, (2) to provide an inservice training component for regular and special teachers, and (3) to revise and improve the program at the graduate level. (For further information, contact the authors.) 
Table 1

RELATIONSHIP OF TRADITIONAL SPECIAL EDUCATION CATEGORIES TO THE UNIVERSITY OF NORTHERN IOWA NONCATEGORICAL TRAINING FRAMEWORK

\begin{tabular}{|c|c|c|}
\hline Functioning Levels* & Traditional Categories & $\begin{array}{c}\text { lowa State Certification Levels and } \\
\text { Approval Areas }\end{array}$ \\
\hline Secondary & \multirow{4}{*}{$\begin{array}{l}\text { EDUCABLE MENTALLY RETARDED } \\
\text { TRAINABLE MENTALLY RETARDED } \\
\text { SPECIFIC LEARNING DISABILITY } \\
\text { EMOTIONALLY AND SOCIALLY MALADJUSTED } \\
\text { PROFOUNDLY AND SEVERELY HANDICAPPED }\end{array}$} & $\begin{array}{l}\text { Endorsement } 20 \text { (Grades } 7-12 \text { ) Approval } \\
\text { areas-mental retardation, emotionally dis- } \\
\text { turbed, specific learning disabilities }\end{array}$ \\
\hline Intermediate & & $\begin{array}{l}\text { Endorsement } 10 \text { (Grades K-9) Approval } \\
\text { areas-mental retardation, emotionally dis- } \\
\text { turbed, specific learning disabilities }\end{array}$ \\
\hline Primary & & $\begin{array}{l}\text { Endorsement } 10 \text { (Grades K-9) Approval } \\
\text { areas-mental retardation, emotionally dis- } \\
\text { turbed, specific learning disabilities }\end{array}$ \\
\hline Pre-Academic & & $\begin{array}{l}\text { Endorsement } 53 \text { Approval Areas-mental } \\
\text { retardation, emotionally disturbed, specific } \\
\text { learning disabilities }\end{array}$ \\
\hline
\end{tabular}

*Trainees may choose a combination of these levels.

\section{REFERENCES}

Blatt, B. The preparation of special education personnel. Review of Educational Research, 1966, 36, 151-161.

Combs, R. H. \& Harper, J. L. Effects of labels on attitudes of educators toward handicapped children. Exceptional Children, 1967, 33, 399-404.

Cruickshank, W. M. Special education, the community and constitutional issues. Paper presented at the Spring Lecture Series, University of Virginia, Charlottesville, April, 1971.

Deno, E. Special education as developmental capital. Exceptional Children, 1970, 37, 229-237.

Dunn, L. M. Special education for the mildly retarded-Is much of it justifiable? Exceptional Children, 1968, 35, 5-24.

Elam, S. Performance-based teacher education: What is the state of the art? PBTE Series: No. 1. Washington, DC: American Association of Colleges for Teacher Education, 1971.

Elbers, G. W. The education professions 1971-72, part III-Supply of and demand for special education personnel. U.S. Printing Office, 1973.

Elfenbein, E. Performance based teacher education programs: $A$ comparative description. PBTE Series: \#8. Washington DC: American Association of Colleges for Teacher Education, 1972.

Goffman, E. Stigma: Notes on the management of spoiled identity. Englewood Cliffs, NJ: Prentice Hall, 1963.
Greer, W. C. Excerpts from testimony presented the House of Representatives Subcommittee on Labor-HEW appropriations regarding fiscal year 1970 appropriations for educational improvement of the handicapped. Arlington, Virginia: Council for Exceptional Children, 1970.

Heller, H. W. Training of professional personnel. Exceptional Children, 1968, 34, 539-543.

Johnson, G. O. Special education for the mentally handicapped-A paradox. Exceptional Children, 1962, pp. 62-69.

Lilly, M. S. Special education: A teapot in a tempest. Exceptional Children, 1970, 35, 43-49.

Lilly, M. S. A training based model for special education. Exceptional Children, 1971, 37, 745-749.

Martin, E. W. Individualism and behaviorism as future trends in educating handicapped children. Exceptional Children, 1972, 38, 517-525.

Menninger, K. Psychiatrists use dangerous words. The Saturday Evening Post, 1964, 237, 12-14.

Nelson, C. C. \& Schmidt, L. J. The question of the efficacy of the special class. Exceptional Children, 1971, 37, 381-384.

Peter, L. J. Prescriptive teaching system: Classroom instruction. New York: McGraw Hill, 1972a.

Peter, L. .J. Prescriptive teaching system: Individual instruction. New York, McGraw Hill, 1972 b.

Reynolds, M. C. \& Balow, B. Categories and variables in special education. Exceptional Children, 1972, 38, 357-366. 